\title{
AVALIAÇÃO DA PRESENÇA DE ANTIBIÓTICO EM LEITE CRU REFRIGERADO
}

\author{
Gabriella Silva de Aguiar ${ }^{1}$ \\ Alessandra de Fátima Ulisses ${ }^{2}$ \\ Larissa Rodrigues Gomes ${ }^{3}$ \\ Luan Ítalo Rebouças Rocha ${ }^{4}$ \\ Maria Isabel Suhet ${ }^{5}$
}

Resumo: Resíduos de antimicrobianos no leite não são eliminados no tratamento térmico e sua presença pode causar problemas de saúde pública, surgimento de resistência bacteriana e prejuízos econômicos. 0 objetivo do presente trabalho foi avaliar a presença de resíduo de antibióticos no leite cru refrigerado destinado ao processamento. Foram analisadas amostras de 15 tanques de refrigeração, de propriedades rurais no município de Alegre-ES no período de agosto a dezembro de 2015, utilizando o teste eclipse $50 \AA$. Das amostras avaliadas, 4 (26,7\%) foram positivas e 11 (73,3\%) negativas. Das amostras positivas, 50\% foram de tanques individuais e $50 \%$ de coletivos, indicando que o uso desse tipo de medicamento independe da capacidade produtiva. Em entrevista, os produtores não admitiram usar ou terem feito uso recente de antibióticos nos animais em lactação, isso nos remete a falta de conscientização desses para o perigo dessa prática. Portanto, há necessidade de maior fiscalização em relação à qualidade do leite na região, estudos complementares envolvendo maior número de produtores e um trabalho de caráter educacional.

Palavras-chave: Qualidade do leite; Resíduos; Saúde pública.

\footnotetext{
1 Licenciatura em Ciências Biológicas/Instituto Federal do Espírito Santo, campus Alegre, Brasil. E-mail: Gabriella.aguiar23@gmail.com.

2 Bacharelado em Ciências Biológicas/Instituto Federal do Espírito Santo, campus Alegre, Brasil. E-mail: afulisses@ifes.edu.br.

3 Engenharia Florestal/Universidade Federal do Espírito Santo, campus Alegre, Brasil. E-mail: larissah_rodrigues@hotmail.com.

4 Licencitura em Ciências Biológicas/Instituto Federal do Espírito Santo, campus Alegre, Brasil. E-mail: luanitalo@hotmail.com.

5 Docente no curso de Agroindústria/Instituto Federal do Espírito Santo, campus Alegre, Brasil. E-mail: misuhet@ifes.edu.br.
} 